\title{
Positron-Emission Tomography and Personality Disorders
}

Peter F. Goyer, M.D., Paul J. Andreason, M.D., William E. Semple, Ph.D., Anita H. Clayton, M.D., Anna C. King, B.S., Beth A. Compton-Toth, B.A., S. Charles Schulz, M.D., and Robert M. Cohen, M.D.

This study used positron-emission tomography to examine cerebral metabolic rates of glucose (CMRG) in 17 patients with DSM III-R diagnoses of personality disorder. Within the group of 17 personality disorder patients, there was a significant inverse correlation between a life history of aggressive impulse difficulties and regional $C M R G$ in the frontal cortex of the transaxial plane approximately $40 \mathrm{~mm}$ above the canthomeatal line $(C M L)(r=-.56, \mathrm{p}=0.17)$. Diagnostic groups included antisocial $(\mathrm{n}=6)$, borderline $(\mathrm{n}=6)$, dependent $(\mathrm{n}=2)$, and narcissistic $(\mathrm{n}=3)$.
Regional CMRG in the six antisocial patients and in the six borderline patients was compared to a control group of 43 subjects using an analysis of covariance with age and sex as covariates. In the borderline personality disorder group, there was a significant decrease in frontal cortex metabolism in the transaxial plane approximately $81 \mathrm{~mm}$ above the CML and a significant increase in the transaxial plane approximately $53 \mathrm{~mm}$ above the $C M L$ $(\mathrm{F}[1,45]=8.65, \mathrm{p}=.005 ;$ and $\mathrm{F}[1,45]=7.68, \mathrm{p}=$ .008 , respectively). [Neuropsychopharmacology 10:21-28, 1994]
KEY WORDS: Positron-emission tomography; Cerebral glucose metabolism; Personality disorder; Borderline personality disorder; Antisocial personality disorder; Regional cerebral metabolic rate of glucose

Cerebrospinal fluid (CSF) 5-hydroxyindoleacetic acid (5-HIAA) has been shown to inversely correlate with alife history of aggressive impulse difficulties in patients with personality disorder diagnoses (Brown et al. 1979). This initial study examined 26 patients from nine different personality disorder diagnostic groups. A subse-

From the Neuropsychiatric Imaging Division, Department of Psychiatry (PFG, WES, BAC, SCS), Case Western Reserve University Medical School and University Hospitals, Cleveland, Ohio; Clinical Brain Imaging Section (PJA, ACK, RMC), National Institute of Mental Health, Bethesda, Maryland; and the Department of Behavioral Medicine and Psychiatry (AHC), University of Virginia Medical School, Charlottesville, Virginia.

Address correspondence to: Peter F. Goyer, M.D., Director, Neuropsychiatric Imaging Division, Department of Psychiatry at University Hospitals, 2040 Abington Road, Cleveland, Ohio 44106.

Received November 12, 1992; revised August 24, 1993; accepted August 27, 1993. quent study by the same group (Brown et al. 1982) focused on the relationship between aggressive impulse difficulty and CSF 5-HIAA in a single axis II diagnostic category, specifically, borderline personality disorder (BPD). A statistically significant inverse correlation between CSF 5-HIAA and a life history of aggressive impulse difficulty was found in both studies. Other researchers have expanded these findings (Linnoila et al. 1983; Lidberg et al. 1985; van Praag 1986; Virkkunen et al. 1987; Roy et al. 1988).

Consistent with animal and human postmortem studies documenting serotonin subtype-2 (5-HT) receptors in frontal cortex, Wong et al. (1984) documented in vivo $5-\mathrm{HT}_{2}$ receptor uptake in human frontal cortex using positron-emission tomography (PET) and ${ }^{11} \mathrm{C}-\mathrm{N}$ methylspiperone. Using PET and 18-fluorodeoxyglucose, Benkelfat et al. (1989) found that the serotonergic drug, clomipramine, reduced abnormally high values of regional cerebral metabolic rate of glucose (rCMRG) in the orbital frontal cortex of patients with obsessivecompulsive disorder. It is thus possible that rCMRG in the frontal lobes would be related to other allegedly 
serotonergic behaviors such as aggressive impulse difficulties.

Positron-emission tomography has also been used to examine rCMRG in specific nonpsychotic and nonsubstance abuse diagnostic groups, such as obsessivecompulsive disorder (Baxter et al. 1987, 1988, 1989; Benkelfat et al. 1989; Nordahl et al. 1989; Swedo et al. 1989) and panic disorder (Nordahl et al. 1990). For both diagnoses, there were statistically significant increases in rCMRG in the frontal lobes of patients compared to normalcontrol subjects. Some studies of rCMRG in the frontal lobes of patients with schizophrenia or affective disorders have found statistically significant decreases compared to normal controls (Buchsbaum et al. 1984; Baxter et al. 1985, 1989; Cohen et al. 1987, 1989; Martinot et al. 1990). Given the pervasive involvement of the frontal lobe in axis I disorders, the question arises as to whether rCMRG differs in the frontal lobes of axis II disorders compared to normal controls.

The present study was undertaken to investigate the hypotheses that there will be a significant relationship between frontal lobe rCMRG and a life history of aggressive impulse difficulties and to compare frontal lobe rCMRG for normal controls and personality disorder patients.

\section{METHODS}

\section{Subjects}

Patients were selected over a 1-year period from male and female military personnel who were admitted to the inpatient ward at the National Naval Medical Center. All patients signed informed consent to voluntarily participate and none received remuneration. All pa- tients were under the supervision of the same staff attending psychiatrist (AHC). To be included, patients had to have an axis II discharge diagnosis according to DSM III-R. All diagnoses were based on an extensive inpatient evaluation and represented the concurrence of the inpatient treatment team. A diagnosis of "personality disorder, not otherwise specified" with the features of a specific diagnosis was grouped under the specific diagnosis.

Exclusion criteria for both the patients and the normal controls included: no significant medical or neurological illnesses, medication-free for at least 6 weeks for normal controls and at least 2 weeks for the patients; no current alcohol or substance abuse; and, for the normal controls, no present or past psychiatric illness.

In the group of 17 personality disorder patients, there were four diagnostic subgroups: antisocial $(n=$ $6)$, borderline $(n=6)$, dependent $(n=2)$, and narcissistic $(n=3)$. All of the antisocial personality disorders were male. Their average age was $23.0 \pm 3.3$ years. In the BPD group, there were four females and two males with an average age of $24.8 \pm 5.7$ years. Their mean score on the Diagnostic Interview for Borderlines (DIB) was $3.7 \pm 1.6$ (Gunderson et al. 1981). In addition to their personality disorder diagnoses, 13 of 17 patients had an axis I diagnosis as listed in Table 1 . Of these 13 patients, the axis I diagnosis in 10 of them (either major depression or adjustment disorder) was resolved at the time of the PET scan (Table 1). In the group of 17 character disorder patients, there were 12 males and five females. Their average age was $25.2 \pm 4.7$ years. Seven of the 17 patients had a history of alcohol abuse; four of six in the antisocial subgroup, two of six in the borderline subgroup, and one of two in the narcissistic subgroup. Two of these 7 had a history of substance

Table 1. Demographic and Diagnostic Data

\begin{tabular}{lcrlll}
\hline Subject & Age/Sex & MAS & Axis II & \multicolumn{1}{c}{ Axis I } & $\begin{array}{c}\text { Axis I } \\
\text { (resolved at scan time) }\end{array}$ \\
\hline 1 & $28 / \mathrm{M}$ & 12 & Antisocial & Major depression & No \\
2 & $24 / \mathrm{M}$ & 19 & Antisocial & Major depression & Yes \\
3 & $25 / \mathrm{M}$ & 9 & Antisocial & Adjustment disorder & Yes \\
4 & $21 / \mathrm{M}$ & 20 & Antisocial & - & - \\
5 & $19 / \mathrm{M}$ & 30 & Antisocial & - & - \\
6 & $21 / \mathrm{M}$ & 13 & Antisocial & Adjustment disorder & Yes \\
7 & $35 / \mathrm{F}$ & 5 & Borderline & Major depression & Yes \\
8 & $24 / \mathrm{F}$ & 6 & Borderline & Bipolar NOS & No \\
9 & $20 / \mathrm{F}$ & 10 & Borderline & - & - \\
10 & $27 / \mathrm{F}$ & 8 & Borderline & Major depression & Yes \\
11 & $21 / \mathrm{M}$ & 4 & Borderline & Major depression & Yes \\
12 & $21 / \mathrm{M}$ & 9 & Borderline & Adjustment disorder & Yes \\
13 & $28 / \mathrm{M}$ & 18 & Dependent & Adjustment disorder & Yes \\
14 & $18 / \mathrm{M}$ & 18 & Dependent & Major depression & Yes \\
15 & $29 / \mathrm{M}$ & 21 & Narcissistic & Major depression & Yes \\
16 & $27 / \mathrm{M}$ & 14 & Narcissistic & - & - \\
17 & $31 / \mathrm{F}$ & 4 & Narcissistic & Dysthmia & No \\
\hline
\end{tabular}


abuse, one in the antisocial subgroup and the other in the borderline subgroup. All the others denied any history of alcohol or substance abuse.

The normal control group consisted of paid volunteers who responded to advertisements at the National Institute of Mental Health. They were screened for psychiatric and other medical illness by (1) semistructured clinical interview with a psychiatrist (PFG, PJA, et al.), (2) physical examination, and (3) routine laboratory testing. There were 43 subjects in the normal control group; 21 were males and 22 were females. Their average age was $30.2 \pm 9.2$ years. All normal control subjects signed informed consent to participate.

\section{Procedure}

Within 2 days of the PET scan, a modified version of a previously published life history of aggression rating scale was administered to the patients (Brown et al. 1979). This scale contained nine items that were scored from 0 to 4 based on personal interviews with either PFG or AHC. The overall concept of the scale was maintained; but the distinctions between temper tantrums (item 1), nonspecific fighting (item 2), and specific assaults (item 3 ) were modified. As previously published, item 3, "specific assaults on people or property" included specific aggressive behavior directed toward another person, toward animals, toward inanimate objects, or toward self (provided it was defined by the patient as a suicidal gesture and not as an attempt). In this study, all aggressive behavior toward other humans was rated as a single entity in item 2 , which had previously included some but not all human-directed aggression. All aggressive behavior toward inanimate objects was scored in item 1, which had previously included some (temper tantrums) but not all inanimately directed aggression. Item 3 was then scored solely on the basis of its two remaining categories, aggressive behavior directed toward self or toward animals. Tantrums with self-harm or animal harm were scored under item 3 . Furthermore, patients were not asked to distinguish between a suicide gesture and a suicide attempt; either behavior was counted as self-directed aggression. Items 4 through 9 remained unchanged. The items in this modified aggression scale (MAS) are listed in Table 2.

The auditory cortical activation procedure and PET scan methodology have been previously described by several authors including Goyer et al. (1992). Subjects were imaged using a Scanditronix PC-1024 with 256 detectors in each of four rings. Each scan yielded seven transaxial slices with an in-plane FWHM resolution of approximately $6 \mathrm{~mm}$. Four scans were obtained at a separation of $3.8 \mathrm{~mm}$ for a total of 28 slices. Images were reconstructed by converting pixel count values to glucose metabolic rate in units of milligrams of glucose/ $100 \mathrm{~g}$ of tissue/minute (Brooks 1982; Huang et al. 1980;
Table 2. Modified Aggression Scale (MAS)

\begin{tabular}{ll}
$\begin{array}{l}\text { Item } \\
\text { Number }\end{array}$ & \multicolumn{1}{c}{ Behavior } \\
\hline 1 & $\begin{array}{c}\text { Aggressive behavior directed toward } \\
\text { inanimate objects } \\
\text { Aggressive behavior directed toward } \\
\text { other humans } \\
\text { Aggressive behavior directed toward } \\
\text { self or animals }\end{array}$ \\
3 & School discipline \\
4 & Relationship with civilian superiors \\
6 & Antisocial behavior not involving the police \\
7 & Antisocial behavior involving the police \\
8 & Military disciplinary problems not \\
& involving the military judicial system \\
9 & Military disciplinary problems involving the \\
& military judicial system
\end{tabular}

Phelps et al. 1979; Sokoloff et al. 1977). Attenuation correction was based on a transmission scan obtained prior to the emission scan. A tracer input curve was calculated from arterial blood sample data.

\section{Image Analysis}

The image analysis method has also been previously described by several authors including Goyer et al. (1992), and some material from those publications is repeated below. Following reconstruction, images of the five transaxial planes that most closely resembled a PET template based on the atlas of Matsui and Hirano (1978) were selected from the 28 available slices. A schematic of these five planes is given in Figure 1. Their approximate distance from the canthomeatal line (CML) beginning with plane $A$ and continuing through plane E is $94 \mathrm{~mm}, 81 \mathrm{~mm}, 67 \mathrm{~mm}, 53 \mathrm{~mm}$, and $40 \mathrm{~mm}$. For the extraction of rCMRG, 60 rectangular regions of interest (ROIs) were measured in the five atlas-matched planes of which 25 were in the frontal lobes. The plane selection and ROI selections were done according to the previously published methods (Clark et al. 1985; Cohen et al. 1987) and were performed independently by two raters who were unaware of the identity and diagnosis of the individual being evaluated. There was high reliability between the two independent raters with an average intraclass correlation coefficient of .95 across the regions. The standardized atlas levels and ROIs set have been used successfully in a series of previous studies that have defined localized cortical activation during the attention task and that have described localized brain abnormalities in mentally ill patient groups (Cohen et al. 1987, 1988a, 1988b).

For each rater the rCMRG in all cortical ROIs for all five planes were summed and then divided by the total number of cortical ROIs $(n=49)$ to obtain an estimate of the average cortical metabolic rate for each sub- 

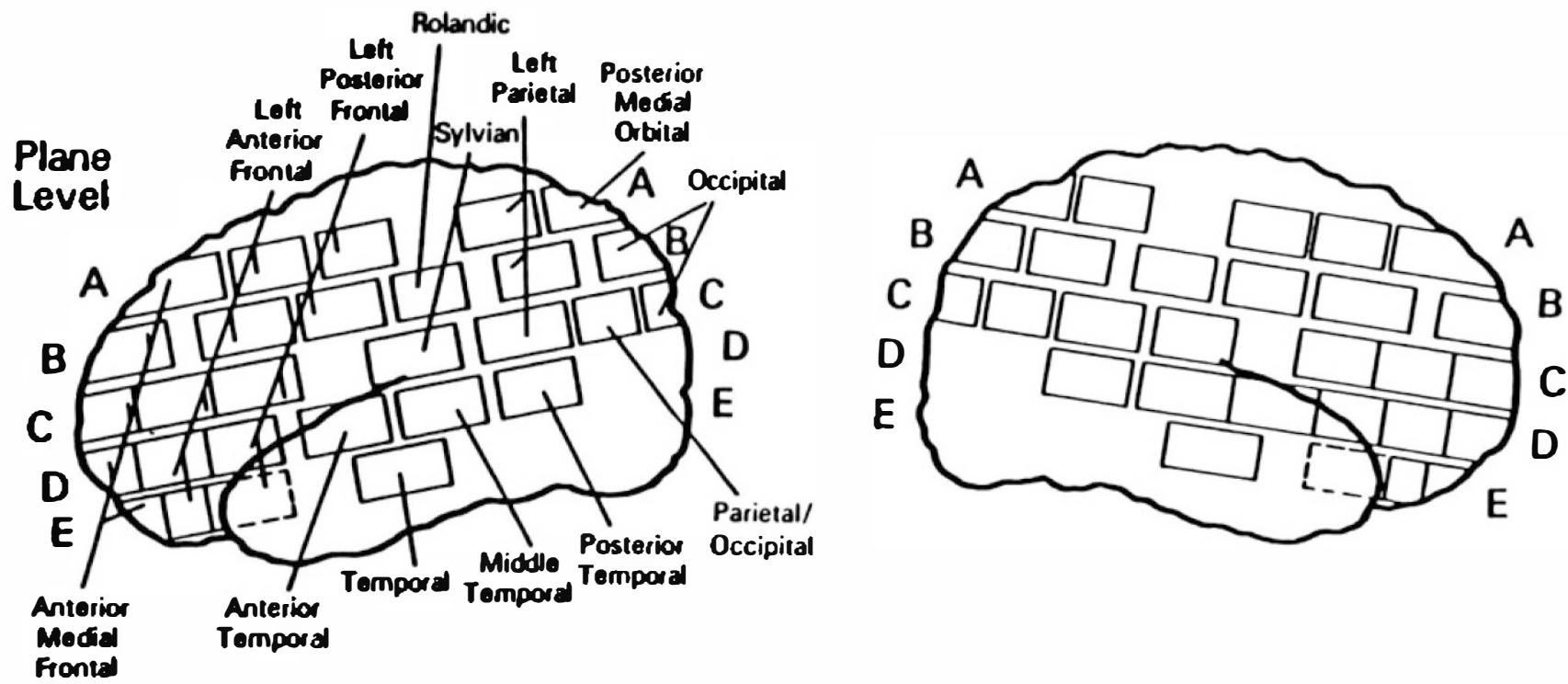

Figure 1. Schematic of ROIs in the left and right hemispheres. Boxes with dashed lines are in frontal cortex with their surface projections on temporal cortex.

ject. This average cortical metabolic rate was used as a denominator for the normalization of rCMRG at each ROI. Intraclass correlation coefficient for average cortical metabolic rate was .99 . The mean of the normalized rCMRG from the two raters was then used in the data analysis.

\section{Statistical Analysis}

Spearman rank ordering statistics were used for correlation coefficients to examine the relationship between aggressive impulse difficulties and rCMRG within the group of 17 personality disorder patients. Except for whole-brain metabolic rate, normalized ROI data were used for all correlation, according to methods previously published (Cohen et al. 1987; Goyer et al. 1992).

Two separate analyses of variance were used to compare personality disorder patients with normal controls for rCMRG in the frontal cortex. Each analysis was a 2 (diagnosis) $\times 5$ (plane) $\times($ ROI within each plane) analysis of covariance (ANOVA) with age and sex serving as covariates to correct for age and sex differences between personality disorder patients and controls. Diagnosis served as a between subjects factor; plane and region served as within subject factors in the analysis. The normal control group was compared with the six antisocial personality disorder patients in the first analysis and with the six BPD patients in the second analysis. The dependent personality disorder group and the narcissistic personality disorder group were not separately analyzed due to the small number of patients in each group, $n=2$ and $n=3$, respectively.

In addition to these analyses of frontal cortex metabolism, a series of exploratory ANCOVAs were performed to test for differences between normals and patients for metabolism in 35 additional brain regions. These 35 additional regions were examined individually.

\section{RESULTS}

All correlations within the group of 17 personality disorder patients were Spearman rank ordered. There was a weak inverse correlation between whole-brain cortical metabolic rate and group rank on the MAS $(r=-.29$, $p=$ not significant). Of the five planes evaluated, this inverse correlation was statistically significant in the $\mathrm{E}$ plane $(r=-.56, p=.017)$. When all contiguous ROIs of the E plane frontal lobe were grouped, there was a significant inverse correlation with absolute scores on the MAS $(r=-.54, p=.025)$. Within the frontal lobe of the E plane, two individual ROIs significantly correlated with absolute scores on the MAS, anterior medial frontal $(r=-.63, p=.006)$ and left anterior frontal $(r=-.56, p=.017)$. These ROIs are approximately $40 \mathrm{~mm}$ above the CML and overlap the superior frontal gyrus and middle frontal gyrus, respectively. The only other ROI in the E plane to show a significant inverse correlation was the right temporal $(r=-.49, p=.04)$. These correlation findings are summarized in Table 3.

No differences were found in frontal cortex metabolism between normals and patients with antisocial personality disorder $(F[1,44]<1)$, and there was no interaction between diagnosis and plane $(F[4,176]<1)$.

For the comparison of BPD patients with normals, there was no main effect of diagnosis $(F[1,45]<1)$ 
Table 3. Statistically Signifıcant Spearman Rank Order Correlation Coefficients for Aggressive Impulse Ratings and rCMRG in 17 Patients with Character Disorder Diagnoses

\begin{tabular}{lcc}
\hline Location & $\boldsymbol{r}$ & $\boldsymbol{p}$ Value \\
\hline E plane & & \\
Orbital frontal cortex & -0.54 & $<0.03$ \\
Anterior medial frontal & -0.63 & $<0.01$ \\
Left anterior frontal & -0.56 & $<0.02$ \\
Right temporal & -0.49 & $<0.04$ \\
\hline
\end{tabular}

but a significant interaction of diagnosis with plane $(F[4,180]=2.88, p=.024)$ indicated the effect of diagnosis should be evaluated separately for each plane using a 2 (diagnosis) by 5 (ROI) ANCOVA.

These analyses revealed significant decreases in frontal cortex metabolism at the B plane $(F[1,45]=8.65$, $p=.005)$ in the BPD group, as well as significant increases in frontal cortex metabolism at the $\mathrm{D}$ plane $(F[1,45]=7.68, p=.008)$ in the BPD group compared to normals. There were no interactions between diagnosis and regions within the B plane $(F[4,180]<1)$ or the $\mathrm{D}$ plane $(F[1,180]<1)$. Normalized frontal cortex glucose metabolic rate at the B plane was $1.077 \pm 0.061$ for normals and $1.004 \pm 0.048$ for patients with BPD. Normalized CMRG in the frontal cortex at the D plane was $1.013 \pm 0.055$ for normals and $1.084 \pm 0.052$ for patients with BPD. Mean metabolic rates at individual regions in the frontal cortex are listed in Table 3 for both normals and BPD patients. Statistically significant differences were found in the anterior and posterior ROIs of the B plane and in the anterior medial and posterior ROIs of the prefrontal cortex in the $\mathrm{D}$ plane. In the B plane, ROIs are approximately $81 \mathrm{~mm}$ above the CML and overlap the middle frontal/inferior frontal gyri and the inferior frontal/precentral gyri, respectively. In the $\mathrm{D}$ plane, these ROIs are approximately $53 \mathrm{~mm}$ above the CML and overlap the superior frontal gyrus and inferior frontal gyrus, respectively. None of the statistically significant differences listed in Table 4 are in regions salient for the CPT.

When exploratory ANCOVAs were performed for nonfrontal cortical regions in all five planes, two regions in the B plane were significantly decreased in the BPD group compared with the normal controls. Mean normalized rCMRG was lower in the posterior cingulate ROI in BPD patients than in normals $[.930 \pm 0.046$ [SEM] and $1.03 \pm .016[S E M]$, respectively, $p<.05]$ and also lower in the left parietal ROI [.933 \pm 0.028 [SEM] and $1.03 \pm 0.010$ [SEM], respectively, $p<.02$ ]. An exploratory ANCOVA was also performed for subcortical ROIs in the basal ganglia and thalamus. No statistically significant differences were found. There were no statistically significant differences in normalized
Table 4. Mean Normalized Glucose Metabolic Rates in Frontal Cortex Regions for Normal Volunteers and Patients with BPD*

\begin{tabular}{|c|c|c|c|c|c|}
\hline & \multicolumn{2}{|c|}{$\begin{array}{l}\text { Normals } \\
(n=45)\end{array}$} & \multicolumn{2}{|c|}{$\begin{array}{l}\text { Patients } \\
(n=6)\end{array}$} & \multirow[b]{2}{*}{$p$ Value } \\
\hline & Mean & SEM & Mean & SEM & \\
\hline \multicolumn{6}{|l|}{ Plane A } \\
\hline Anterior medial & 1.003 & 0.015 & 0.967 & 0.043 & NS \\
\hline Left anterior & 1.044 & 0.016 & 0.997 & 0.045 & NS \\
\hline Right anterior & 1.035 & 0.014 & 1.006 & 0.039 & NS \\
\hline Left posterior & 1.035 & 0.015 & 0.986 & 0.043 & NS \\
\hline Right posterior & 1.018 & 0.012 & 1.003 & 0.035 & NS \\
\hline \multicolumn{6}{|l|}{ Plane B } \\
\hline Anterior medial & 1.030 & 0.011 & 0.966 & 0.030 & 0.054 \\
\hline Left anterior & 1.069 & 0.011 & 1.011 & 0.030 & 0.074 \\
\hline Right anterior & 1.042 & 0.010 & 0.974 & 0.028 & $0.030^{\dagger}$ \\
\hline Left posterior & 1.121 & 0.013 & 1.035 & 0.037 & $0.039 t$ \\
\hline Right posterior & 1.129 & 0.014 & 1.010 & 0.040 & $0.008^{\dagger}$ \\
\hline \multicolumn{6}{|l|}{ Plane C } \\
\hline Anterior medial & 0.994 & 0.012 & 1.029 & 0.034 & NS \\
\hline Left anterior & 1.056 & 0.014 & 1.056 & 0.040 & NS \\
\hline Right anterior & 1.059 & 0.013 & 1.091 & 0.036 & NS \\
\hline Left posterior & 1.083 & 0.014 & 1.126 & 0.040 & NS \\
\hline Right posterior & 1.102 & 0.014 & 1.093 & 0.038 & NS \\
\hline \multicolumn{6}{|l|}{ Plane D } \\
\hline Anterior medial & 0.975 & 0.009 & 1.044 & 0.026 & $0.019^{\dagger}$ \\
\hline Left anterior & 1.050 & 0.011 & 1.109 & 0.030 & 0.072 \\
\hline Right anterior & 1.064 & 0.011 & 1.128 & 0.031 & 0.067 \\
\hline Left posterior & 0.992 & 0.013 & 1.077 & 0.036 & $0.035^{\dagger}$ \\
\hline Right posterior & 0.986 & 0.011 & 1.057 & 0.030 & $0.038^{\dagger}$ \\
\hline \multicolumn{6}{|l|}{ Plane E } \\
\hline Anterior medial & 0.919 & 0.011 & 0.952 & 0.030 & NS \\
\hline Left anterior & 0.940 & 0.014 & 0.964 & 0.040 & NS \\
\hline Right anterior & 0.963 & 0.017 & 0.998 & 0.048 & NS \\
\hline Left posterior & 0.952 & 0.011 & 0.994 & 0.032 & NS \\
\hline Right posterior & 0.962 & 0.014 & 0.992 & 0.040 & NS \\
\hline
\end{tabular}

* Individual regions were analyzed using ANCOVA, with sex and age as covariates.

t $p<.05$.

rCMRG in cortical or subcortical ROIs when the antisocial group was compared with the normal controls.

Personality disorder subjects did not differ significantly from normals for CPT performance. The average values for hits on the CPT were $185.10 \pm 31.44$ for the normals and $170.75 \pm 25.99$ for the personality disorder patients $(p>.10$, two-tailed $t$-test). The average values for false alarms on the CPT were $10.83 \pm$ 21.54 for the normals and $7.37 \pm 6.65$ for the personality disorder patients ( $p>.35$, two-tailed $t$-test). Performance on the CPT was unrelated to any differences between patients and controls in rCMRG: specifically, there were no significant correlations between CPT hits or CPT false alarms and metabolism at any ROI that differed between groups. Furthermore, there was no relationship between CPT performance and life history of aggressive behavior: specifically, there were no significant correlations between CPT hits or CPT false alarms and the MAS. These findings relative to CPT 
are expected because the region of localization of the $\mathrm{CPT}$ is in the right frontal ROI in the $\mathrm{C}$ plane (Cohen et al. 1988).

\section{DISCUSSION}

\section{Aggressive Behavior and rCMRG}

A number of authors have reported increased metabolic rates of glucose in regions of the orbital frontal and prefrontal cortex in patients with obsessive-compulsive disorder compared with normal control groups (Baxter et al. 1987, 1988, 1989; Benkelfat et al. 1989; Nordahl et al. 1989; Swedo et al. 1989). In this study, higher normalized rCMRG in the orbital frontal cortex correlates with a history of fewer aggressive behavior impulse difficulties, and a lower normalized rCMRG correlates with a history of more aggressive behavior impulse difficulties. In a separate study, Raine et al. (1992) compared 22 convicted murderers with 22 age and sexmatched controls and found decreased rCMRG in the orbital frontal and prefrontal cortex of the murderers. These findings would be consistent with our findings of an inverse correlation between aggressive impulse difficulties and orbital frontal rCMRG. It is thus possible that there is both a diagnostic and a symptom inhibition relationship to increased rCMRG in orbital frontal cortex. The potential significance of the inverse correlation in the right temporal region requires additional investigation.

\section{Antisocial Personality Disorder and rCMRG}

Although there was a within group $(n=17)$ correlation of aggressive impulse difficulties with normalized rCMRG in the anterior orbital frontal cortex, there were no statistically significant group mean differences between the subgroup of antisocial personality disorder patients $(n=6)$ and the normal control group $(n=43)$. Because four of the six patients in the antisocial subgroup had a history of alcohol abuse, there is an unlikely possibility that chronic changes in rCMRG from alcohol abuse could have caused sufficient variability in the data to promote a false negative finding. Because there were only six male antisocial personality disorder patients, it is also possible that the statistical analysis that covaried for sex (and age) did not have sufficient power with this small $n$ to achieve statistical significance.

\section{Borderline Personality Disorder and Frontal Lobe rCMRG}

Patients with BPD demonstrated significant differences between normalized rCMRG in two planes of the frontal lobes compared with normal controls, an increase in the $\mathrm{D}$ plane and a decrease in the B plane. As outlined in the beginning of our paper, numerous studies have documented frontal lobe increases in rCMRG for other nonpsychotic and nonsubstance abuse diagnostic groups; these findings, however, have been localized predominantly in the E plane orbital frontal cortex or a combination of orbital frontal and $D$ plane prefrontal cortex. In contrast, the rCMRG increase in the BPD patients is localized in the prefrontal regions of the $D$ plane only. Positron-emission tomography studies in schizophrenia or affective disorder have found statistically significant differences in rCMRG in the prefrontal cortex of the D plane but these were decreases. Significant decreases in normalized rCMRG in the BPD group were found only in the B plane of the frontal lobes. In a PET study of adults with hyperactivity of childhood onset, Zametkin et al. (1990) reported statistically significant bilateral decreases in absolute rCMRG in the frontal lobes of the B plane. Normalized rCMRG was significantly decreased only on the left. With regard to frontal lobe findings, therefore, this group of BPD patients shares some findings with other diagnostic groups but appears to exhibit a unique combination of an increase in CMRG in the D plane frontal lobes and a decrease in the $B$ plane frontal lobes.

Kavoussi et al. (1990) have pointed out discrepancies between various rating scales and BPD as a DSM III diagnosis, so the relatively low average score on the DIB for patients in this study group is not inconsistent with their diagnosis. It does, however, suggest that this group may not be as severely ill as other groups of patients with BPD. This description is further supported by the absence of any axis I diagnosis in five of the six BPD patients at the time of the scan. Also, the scans themselves show no evidence of the $C$ and $D$ plane hypofrontality in patients with schizophrenia or primary affective disorder and no evidence of decreased cortical metabolic rate reported for depressed patients with primary affective disorder (Buchsbaum et al. 1984; Baxter et al. 1985, 1989; Cohen et al. 1987, 1989; Martinot et al. 1990). Consequently, glucose metabolic findings that tend to distinguish this group of BPD patients may differ in a more severely ill group.

\section{Borderline Personality Disorder and Nonfrontal Lobe rCMRG}

In areas other than the frontal lobes, the significance of the $B$ plane cingulate decrease in BPD patients is unclear. The significant decrease in normalized rCMRG in the left posterior parietal ROI of the B plane has, however, been reported by Nordahl et al. (1990) for panic disorder and Goyer et al. (1992) for summer seasonal affective disorder. A trend for a decrease in normalized rCMRG ( $p=.06$ ) was also reported by Nordahl et al. (1989) in a study of patients with obsessive-compulsive 
disorder. Other parietal lobe findings in that study included decreases in the $\mathrm{B}$ plane right posterior parietal ROI $(p=.04)$ and in the C plane left parietal occipital $\mathrm{ROI}(p=.01)$. A biologic correlate for a particular symptom, such as anxiety, may thus exist in the posterior parietal area for several nonpsychotic diagnostic groups.

\section{SUMMARY}

To the authors knowledge, this is the first report of a statistically significant symptom correlation between a life history of aggressive impulse difficulties and rCMRG in the orbital frontal cortex, and the first report of a unique frontal lobe pattern with significant rCMRG decreases in the $B$ plane and significant rCMRG increases in the D plane of patients with BPD. Because of the small number of subjects in this and other preliminary PET studies, replication is essential. Hopefully, this initial study, in combination with other PET studies of personality disorder patients, will contribute to our understanding of BPD and aggressive impulse diffculties.

\section{ACKNOWLEDGMENT}

This work was supported in part by a grant from the Cleveland Foundation.

\section{REFERENCES}

Baxter LR, Phelps ME, Mazziotta JC, Schwartz JM, Gerner RH, Selin CE, Sumida RM (1985): Cerebral metabolic rates for glucose in mood disorders. Arch Gen Psychiatry 42:441-447

Baxter LR, Phelps ME, Mazziotta JC, Guze BH, Schwartz JM, Selin CE (1987): Local cerebral glucose metabolic rates in obsessive-compulsive disorder. A comparison with rates in unipolar depression and in normal controls. Arch Gen Psychiatry 44:211-218

Baxter LR, Schwartz JM, Mazziotta JC, Phelps ME, Pahl JJ, Guze BH, Fairbanks L (1988): Cerebral glucose metabolic rates in nondepressed patients with obsessive-compulsive disorder. Am J Psychiatry 145:1560-1563

Baxter LR, Schwartz JM, Phelps ME, Mazziotta JC, Guze BH, Selin CE, Gerner RH, Sumida RM (1989): Reduction of prefrontal cortex glucose metabolism common to three types of depression. Arch Gen Psychiatry 46:243-250

Benkelfat C, Murphy DL, Zohar J, Hill JL, Grover G, Insel TR (1989): Clomipramine in obsessive-compulsive disorder. Further evidence for a serotonergic mechanism of action. Arch Gen Psychiatry 46:23-28

Brown GL, Goodwin FK, Ballenger JC, Goyer PF, Major LF (1979): Aggression in humans correlates with cerebrospinal fluid amine metabolites. Psychiatry Res 1:131-139

Brown GL, Ebert MH, Goyer PF, Jimerson DC, Klein WJ, Bun- ney WE, Goodwin FK (1982): Aggression, suicide, and serotonin: Relationships to CSF amine metabolites. Am J Psychiatry 139:741-746

Brooks RA (1982): Alternative formula for glucose utilization using labeled deoxyglucose. J Nucl Med 23:538-539

Buchsbaum MS, Cappelletti J, Ball R, Hazlett E, King AC, Johnson J, Wu J, DeLisi LE (1984): Positron emission tomographic image measurement in schizophrenia and affective disorders. Ann Neurol 15:S157-S165

Clark C, Carson R, Kessler R, Margolin R, Buchsbaum M, DeLisi L, King C, Cohen R (1985): Alternative statistical models for the examination of clinical positron emission tomography/fluorodeoxyglucose data. J Cereb Blood Flow Metab 5:142-150

Cohen RM, Semple WE, Gross M, Nordahl TE, DeLisi LE, Holcomb HH, King AC, Morihisa JM, Pickar D (1987): Dysfunction in a prefrontal substrate of sustained attention in schizophrenia. Life Sci 40:2031-2039

Cohen RM, Semple WE, Gross M, Holcomb HH, Dowling MS, Nordahl TE (1988a): Functional localization of sustained attention: Comparison to sensory stimulation in the absence of instruction. Neuropsychiatry Neuropsychol Behav Neurol 1:3-20

Cohen RM, Semple WE, Gross M, Nordahl TE, HolcombHH, Dowling MS, Pickar D (1988b): The effect of neuroleptics on dysfunction in a prefrontal substrate of sustained attention in schizophrenia. Life Sci 43:1141-1150

Cohen RM, Semple WE, Gross M, Nordahl TE, King AC, Pickar D, Post RM (1989): Evidence for common alterations in cerebral glucose metabolism in major affective disorders and schizophrenia. Neuropsychopharmacology 2:241-254

Goyer PF, Schulz PM, Semple WE, Gross M, Nordahl TE, King AC, Wehr TA, Cohen RM (1992): Cerebral glucose metabolism in patients with summer seasonal affective disorder. Neuropsychopharmacology 7:233-240

Gunderson JG, Kolb JE, Austin V (1981): The diagnostic interview for borderline patients. Am J Psychiatry 138: 896-903

Huang SC, Phelps ME, Hoffman EJ, Sinderis K, Selin CJ, Kuhl DE (1980): Noninvasive determination of local cerebral metabolic rate of glucose in man. Am J Physiol 138: E69-E82

Kavoussi RJ, Coccaro EF, Klar HM, Berstein D, Siever LJ (1990): Structured interviews for borderline personality disorder. Am J Psychiatry 147:1522-1525

Lidberg L, Tuck JR, Asberg M, Scalia-Tomba GP, Bertilsson L (1985): Homicide, suicide and CSF 5-HIAA. Acta Psychiatr Scand 71:230-236

Linnoila M, Virkkunen M, Scheinin M, Nuutila A, Rimon R, Goodwin FK (1983): Low cerebrospinal fluid 5-hydroxyindoleacetic acid concentration differentiates impulsive from nonimpulsive violent behavior. Life Sci 33:26092614

Martinot JL, Hardy P, Feline A, Huret JD, Mazoyer B, AttarLevy D, Pappata S, Syrota A (1990): Left prefrontal glucose hypometabolism in the depressed state: A confirmation. Am J Psychiatry 147:1313-1317

Matsui T, Hirano A (1978): An Atlas of the Human Brain for Computerized Tomography. Tokyo, Igaku-Shoin 
Metter EJ, Riege WH, Kuhl DE, Phelps ME (1984): Cerebral metabolic relationships for selected brain regions in healthy adults. J Cereb Blood Flow Metab 4:1-7

Nordahl TE, Benkelfat C, Semple WE, Gross M, King AC, Cohen RM (1989): Cerebral glucose metabolic rates in obsessive-compulsive disorder. Neuropsychopharmacology 2:23-28

Nordahl TE, Semple WE, Gross M, Mellman TA, Stein MB, Goyer P, King AC, Uhde TW, Cohen RM (1990): Cerebral glucose metabolic differences in patients with panic disorder. Neuropsychopharmacology 3:261-272

Phelps ME, Huang SC, Hoffman EJ, Selin C, Sokoloff L, Kuhl DE (1979): Tomographic measurement of local cerebral glucose metabolic rate in humans with [F-18]2-fluoro-2deoxy-D-glucose: Validation of method. Ann Neurol 6:371-388

Raine A, Buchsbaum MS, Stanley J, Lottenberg S, Abel L, Stoddard J (1992): Selective reductions in pre-frontal glucose metabolism in murderers assessed with positron emission tomography. Psychophysiology 29 (4A):S58

Roy A, Adinoff B, Linnoila M (1988): Acting out hostility in normal volunteers: Negative correlation with levels of 5HIAA in cerebrospinal fluid. Psychiatry Res 24:187-194

Sokoloff L, Reivich M, Kennedy C, Des Rosiers MH, Patlak CS, Pettigrew KD, Sakurada O, Shinohara M (1977): The $\left[{ }^{14} \mathrm{C}\right]$ deoxyglucose method for the measurement of local cerebral glucose utilization: Theory, procedure, and normal values in the conscious and anesthetized albino rat. J Neurochem 28:897-916

Swedo SE, Schapiro MB, Grady CL, Cheslow DL, Leonard HL, Kumar A, Friedland R, Rapoport SI, Rapoport JL (1989): Cerebral glucose metabolism in childhood-onset obsessive-compulsive disorder. Arch Gen Psychiatry 46:518-523

van Praag HM (1986): (Auto)aggression and CSF 5-HIAA in depression and schizophrenia. Psychopharmacol Bull 22: $669-673$

Virkkunen M, Nuutila A, Goodwin FK, Linnoila M (1987): Cerebrospinal fluid monaoamine metabolite levels in male arsonists. Arch Gen Psychiatry 44:241-247

Wong DF, Wagner HN, Dannals RF, Links JM, Frost JJ, Ravert HT, Wilson AA, Rosenbaum AE, Gjedde A, Douglass $\mathrm{KH}$, Petronis JD, Folstein MF, Toung JKT, Burns HD, Kuhar MJ (1984): Effects of age on dopamine and serotonin receptors measured by positron tomography in the living human brain. Science 226:1393-1396

Zametkin AJ, Nordahl TE, Gross M, King AC, Semple WE, Rumsey J, Hamburger S, Cohen RM (1990): Cerebral glucose metabolism in adults with hyperactivity of childhood onset. N Engl J Med 323:1361-1366 